\title{
COVID 19 - The Italian Perspective
}

\section{Michele Danilo Pierri ${ }^{1}$, Jacopo Alfonsi ${ }^{1}$, Mariano Cefarelli ${ }^{1}$, Paolo Berretta ${ }^{1}$, and Marco Di Eusanio $^{1}$}

${ }^{1}$ Lancisi Cardiovascular Center, Polytechnic University of Marche Ancona, IT

August 5, 2020

\begin{abstract}
Italy has been hard hit by SarV CO2 infection with more than 240,000 cases and 35,000 deaths. During the acute phase of the pandemic the italian government decided on the lockdown which lasted about 2 months. During this period all surgical activities were limited to non-deferable procedures only. The sudden closure posed problems with the management of the heart surgery waiting which at that time included 135 patients. Among these were selected cases with the worst clinical characteristics that were progressively operated on. Compared with a similar period in 2019, the cardiac surgery activity of the "Lancisi Cardiovascular Center" in Ancona has been reduced by $65 \%$. With pandemic mitigation, heart surgery activity has gradually resumed but many open questions remain. Above all, there is the problem of living with a low but persistent level of presence of the virus with the need to organize the activity in order to ensure patients and staff safety and an optimal level of performance.
\end{abstract}

\section{Hosted file}

Covid - Submission.doc available at https://authorea.com/users/348861/articles/474055-covid19-the-italian-perspective

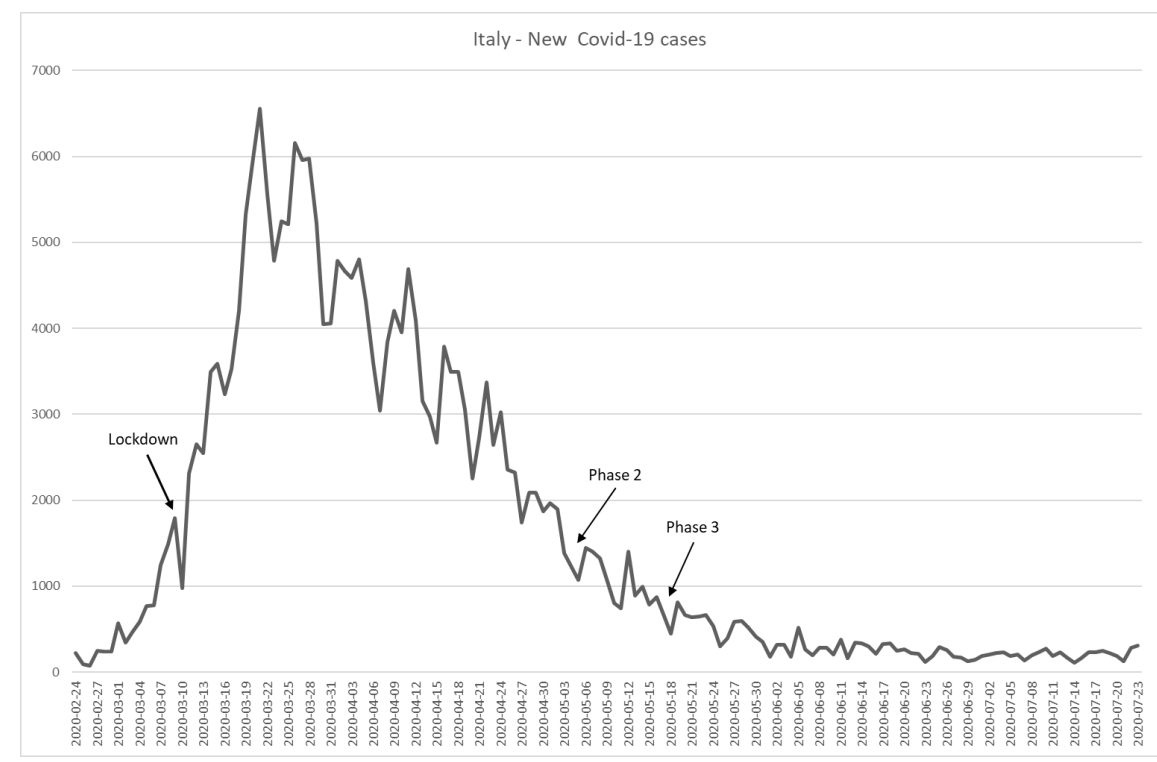



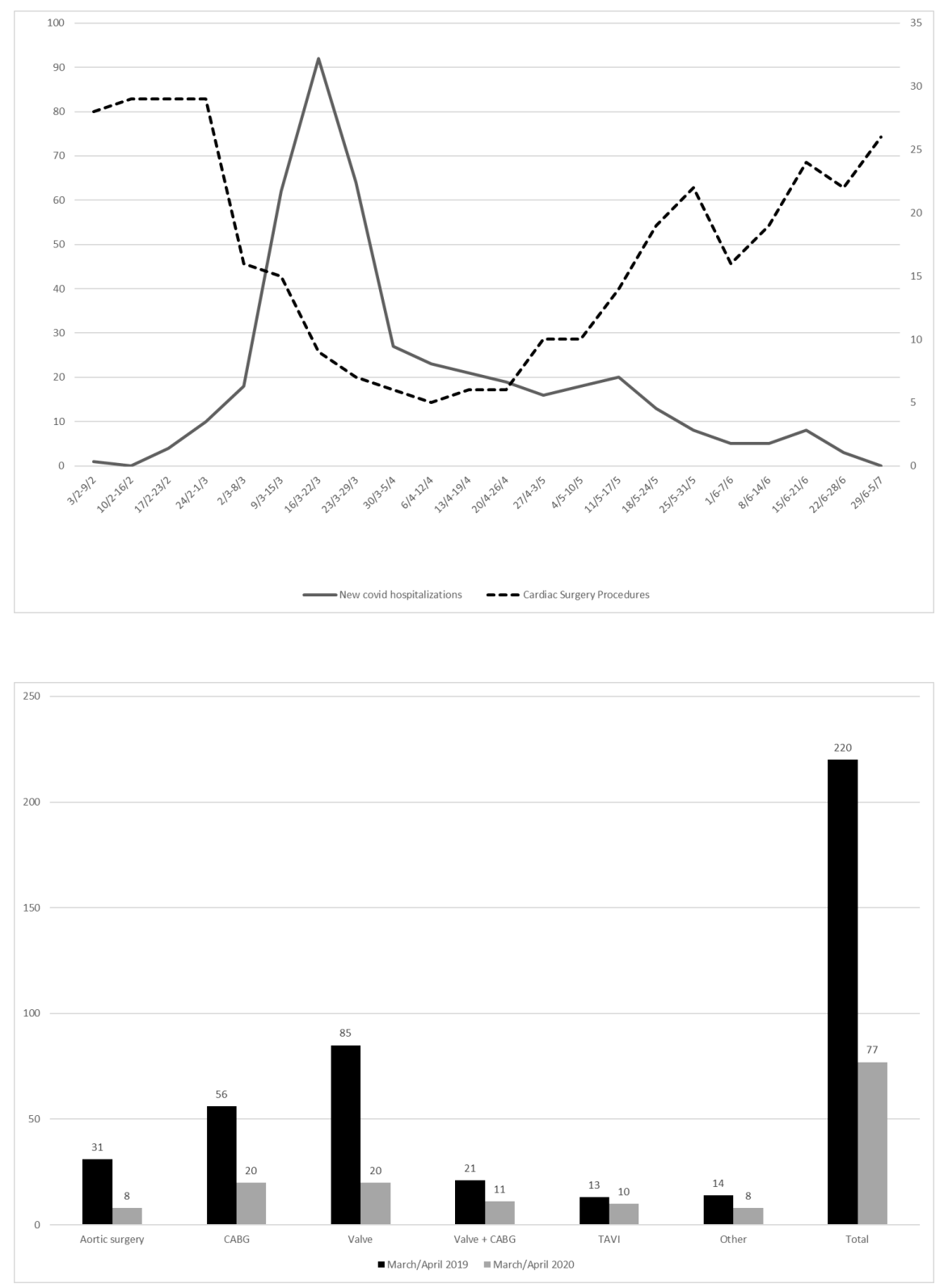